Maria de Fátima Sousa e Silva

Coordenação

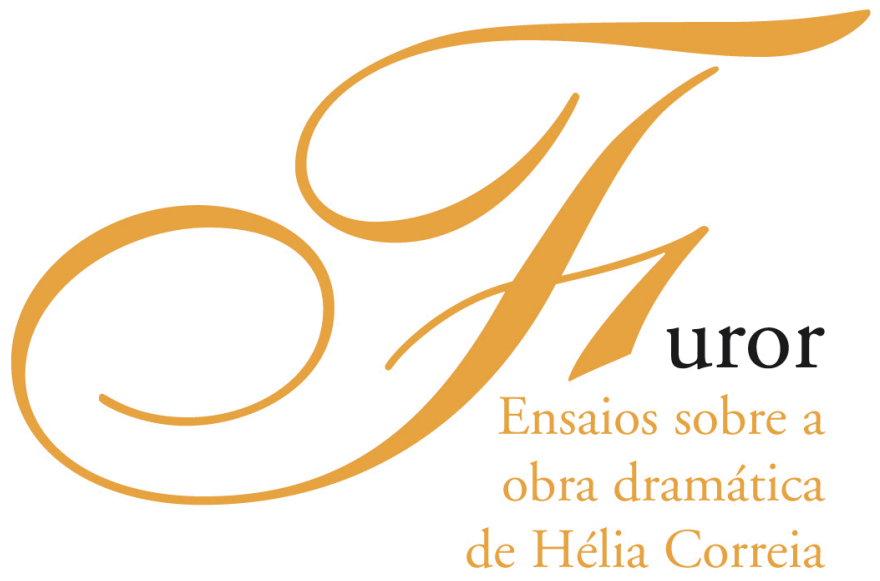

- COIMBra 2006 
COORDENAÇÃO EDITORIAL

Imprensa da Universidade de Coimbra

URL: http//www.imp.uc.pt

\author{
CONCEPÇÃO GRÁFICA \\ António Barros \\ PAGINAÇÃO \\ Inova \\ EXECUÇÃO GRÁFICA \\ Inova - Artes Gráficas \\ Porto
}

ISBN

972-8704-94-1

DEPÓSITO LEGAL

247166/06

C OUTUBRO, 2006, IMPRENSA DA UNIVERSIDADE DE COIMBRA

OBRA PUBLICADA COM O APOIO DE:

Centro de Estudos Clássicos e Humanísticos

FCT Fundação para a Ciência e a Tecnologia

MINISTÉRIO DA CIÊNCIA, TECNOLOGIA E ENSINO SUPERIOR Portugal 
Maria de Fátima Sousa e Silva

Coordenação

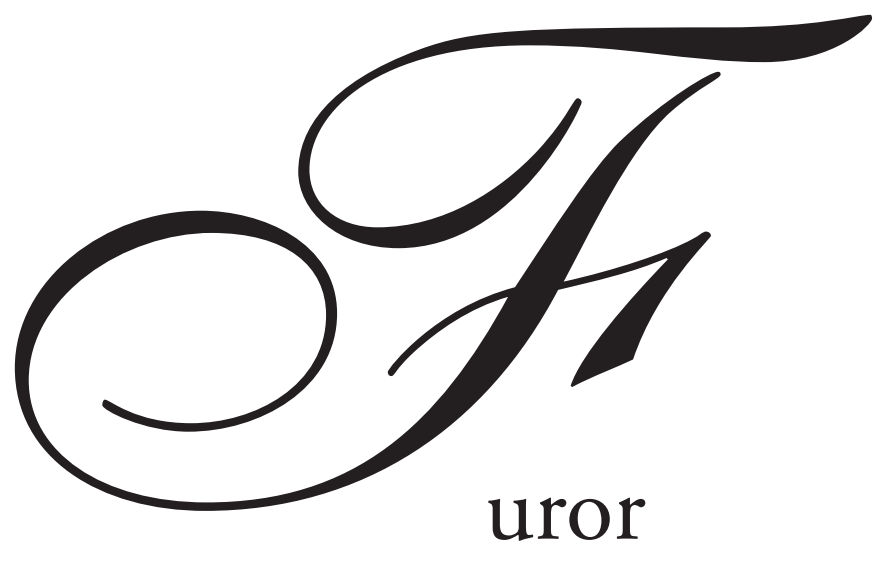

\author{
Ensaios sobre a \\ obra dramática \\ de Hélia Correia
}



Isabel Capeloa Gil

Universidade Católica Portuguesa - Lisboa

\title{
ESPECTROS LITERÁRIOS: PERDIÇÃO DE HÉLIA CORREIA ${ }^{1}$
}

\author{
Distance - Woman averts truth - the philosopher. \\ She bestows the idea. And the idea withdraws, \\ becomes transcendant, inacessible, seductive. \\ It beckons from afar. It veils flout in the distance. \\ The dream of death begins. It is a woman.
}

Jacques Derrida

No ensaio Das Unheimliche, Sigmund Freud define o estranho como sendo "[...] aquele tipo de terror que reside na reconfiguração de algo habitual e nosso conhecido». ${ }^{2}$ Esquecendo a dimensão do medonho e do tenebroso a ela inerente, a configuração freudiana é de facto pertinente para designar a nossa aproximação ao drama Perdição. Exercício sobre Antígona, de 1991, que constitui a primeira incursão da novelista Hélia Correia no âmbito da dramaturgia. Construído em três planos, o plano dos vivos - que decorre num pátio do palácio de Tebas e depois na sala do trono -, o plano das mortas - situado na penumbra e desenrolando-se num campo de asfódelos - e o plano em que se encontra Tirésias, o adivinho cego que preside aos acontecimentos e os comenta, este drama representa um esforço de actualização do conhecido mito

\footnotetext{
${ }^{1}$ Este trabalho foi apresentado no $6^{\circ}$ Congresso Internacional da Associação Internacional de Lusitanistas, que decorreu no Rio de Janeiro em Agosto de 1999. Publicado em Actas do $6^{\circ}$ Congresso da Associação Internacional de Lusitanistas, CD-Rom, AIL, Rio de Janeiro 2001.

${ }^{2}$ Sigmund Freud, Gesammelte Werke. Studienausgabe Band IV (Hg.Alexander Mitscherlich, Angela Richards et al.), Frankfurt am Main, Fischer ,1987, p. 250.
} 
de Antígona que conceptualmente invoca o modelo da estranheza freudiana. A designação «Exercício» aplica-se magistralmente a esta forma de reconfiguração da história mítica, que questiona o mito tradicional, a estrutura clássica do drama, instituindo através da diferância (différance) dos três planos expostos uma visão renovada da tragédia sofocliana. Esta versão trágica funciona como signo inicial de uma constituição cultural de sentido ${ }^{3}$ que se enuncia nas antinomias centrais do texto - as oposições entre o Estado e o Indivíduo, o público e o privado, o lugar dos homens e das mulheres - bem como na estrutura ritual do mesmo, assinalando o modo como as estruturas de violência se revelam actos fundadores de cultura, tornando-se afinal produtivas para a evolução sócio-cultural. ${ }^{4}$

Embora integrando a tradição portuguesa de reflexão dramática sobre o mito de Antígona, que no século XX conta com as contribuições, entre outros, de Júlio Dantas, António Sérgio, ou António Pedro, o drama de Hélia Correia apresenta-se como uma experiência dramática limítrofe. Assim, actualiza numa

\footnotetext{
${ }^{3} \mathrm{O}$ mito de Antígona é tratado por alguns classicistas, nomeadamente por Manfred Fuhrmann, como sendo fundamentalmente uma criação sofocliana sobre um tema tradicional da saga tebana, mostrando assim a tragédia de Sófocles como uma mera elaboração formal, e portanto sígnica de um início, que não sendo constituído pelo texto sofocliano, nele se encontra mesmo que seja por oposição. Vd.Manfred Fuhrmann, «Mythos als Wiederholung in der griechischen Tragödie und im Drama des 20. Jahrhunderts", Terror und Spiel. Probleme der Mythenrezeption, (Manfred Fuhrmann ed.), München, Wilhelm Fink Verlag, 1971, p.121 e Hans-Thies Lehmann, Theater und Mythos. Die Konstitution des Subjekts im Diskurs der antiken Tragödie, Stuttgart, Verlag J. P. Metzler, 1991, p.100. Sobre as várias versões da saga tebana e da história de Antígona cf. Isabel Capeloa Gil, Mitografias. Figurações de Antígona, Cassandra e Medeia no Drama de Expressão Alemã do Século XX (Diss. Dout.), Lisboa, Universidade Católica Portuguesa, 2002, pp. 35-52.

A reconversão do mito por Hélia Correia, mais do que a reescrita de um texto original sofocliano, afirma-se como construção signíca determinada por condicionantes históricas, políticas e filosóficas que, aporisticamente, remetem para um início em contínua construção. A explicação de Geoffrey Bennington no texto Jacques Derrida a propósito da negação do fundamento na filosofia de Derrida é pertinente para elucidar esta relação do texto : "Saying that there is no secure starting point does not mean that one starts at random. You always start somewhere, but that somewhere is never just anywhere.[...] The somewhere where you always start is overdetermined by historical, political, philosophical, and phantasmatic structures that in principle can never be fully controlled or made explicit (GL,5a). The starting point is in a way radically contingent, and that it be thus contingent is a necessity.» Geoffrey Bennington, Jacques Derrida, Chicago, The University of Chicago Press, 1993, pp.20-22.

${ }^{4}$ Cf. René Girard, Das Heilige und die Gewalt, Stuttgart, Fischer, 1992.
} 
dialéctica entre ausência e presença, um exercício sobre a vitalidade da tradição clássica, um exercício formal sobre as possibilidades do dramático, uma vez sublimadas as grandes oposições do texto sofocliano, mas essencialmente, e mais do que um exercício sobre o trágico, um indagar das possibilidades da existência feminina, quer como repositora da memória no mundo masculino da história quer como entidade tutelar da afectividade e do amor. Este tema constitui-se, aliás, como tópico central do discurso das mulheres, evocado também, segundo a mesma estratégia de estranheza, no título Perdição que surge como intertexto subversivo da obra canónica Amor de Perdição de Camilo Castelo Branco.

O drama de Hélia Correia é uma construção dramática intertextual e autoreflexiva, ${ }^{5}$ construindo a personagem Antígona com uma ousadia que a faz digna herdeira de figurações modernas como a de Anouilh. Esta Antígona possui um libertarismo quase feminista, que a afasta da figura submissa da Antiguidade, a quem Luce Irigaray denomina femme-tombeau, ${ }^{6}$ a mulher que renega a sua identidade para afirmar a lei do pai corporizada na inabalável defesa do direito de sepultura para o irmão Polinices, um tema secundário no texto de Hélia Correia. O tempo e o lugar das mulheres no tema antigónico constituem afinal o espaço central desta reconfiguração. A própria construção do texto, iniciada com o ditirambo dionisíaco entoado pelo coro das bacantes, introduz o tema central da feminilidade, apontando desde logo para a dimensão abissal, a um tempo criadora e destruidora, do feminino, ${ }^{7}$ um Leitmotiv que percorre todo o texto.

O exercício de Hélia Correia revela-se igualmente como uma experiência de poética auto-reflexiva, confrontando as possibilidades de existência feminina

\footnotetext{
5 Jonathan Culler, Literary Theory. A Very Short Introduction, Oxford, Oxford University Press, 1997, p. 34 .

${ }^{6}$ Luce Irigaray, Ethik der sexuellen Differenz, (trad. Xenia Rajewsky), Frankfurt am Main, Suhrkamp, 1991, p. 140.

7 A íntima ligação entre o acto sexual e a morte é assinalada por Georges Bataille, O Erotismo, Lisboa, Antígona, 1987, p. 24.
} 
na economia dramática através de uma construção triádica, em três planos, três ritmos, três tempos e três espaços. Temos assim no início do drama o coro das bacantes, uma espécie de prólogo que desloca o espectador do tempo e do espaço da representação e o faz regressar ao tempo primevo do mito, um tempo circular, cíclico como o próprio movimento da dança de roda que as bacantes encenam, ${ }^{8}$ e a circularidade da história do deus Dioniso que preside a este hino, conferindo à acção a dimensão de tempo mitológico, um tempo fora do tempo, que se subtrai à história e evade a memória:

\section{Toda a bistória do mundo}

há-de esvair-se

como as nossas pegadas.

Deus da treva

e do uivo.

Fiquem uivos

e trevas

porque não há memória

e a alma esquece,

seja qual for o modo de existir. (p.21)

A temporalidade da acção inscreve-se deste modo num ciclo de eterno retorno, numa circularidade aporística que se define na exortação dialéctica do presente, passado e futuro do discurso horizontal de Tirésias. A própria mancha gráfica que marca o discurso de Tirésias como um discurso horizontal, constituindo os outros dois planos discursivos, o dos vivos, como uma coluna vertical à esquerda, e o das mortas, uma coluna à direita, insere o discurso do vidente na ordem horizontal da escrita da história, que percorre o tempo da presença

\footnotetext{
8 «À roda, à roda,à roda,/ raparigas./ temos o deus em nós./ É isto o amor?» Hélia Correia, Perdição. Exercício sobre Antígona. Florbela. Teatro, Lisboa, Publicações Dom Quixote, 1991, p.19.
} 
dos vivos e o da ausência das mortas. Tirésias figura, na verdade, como um xamã, ${ }^{9}$ uma personagem dramática e avatar da autora, ${ }^{10}$ um mediador entre fronteiras, entre o tempo do mito e o tempo da história, o público/leitor e o teatro, os homens e as mulheres ${ }^{11}$ - que pela sua experiência de bissexualidade bem conhece $-{ }^{12}$, os mortos e os vivos. Na economia da acção, Tirésias activa uma representação fantasmática, exorta os espíritos do passado mitológico e encena-os, distanciando epicamente a representação da vivência/experiência, e revelando o processo dramático como um processo espectrógeno, ou seja que exorta à aparição de fantasmas.

- Sentir-se-ão os que vêem ao abrigo do que é visto? Acomodar-se-ão no escasso conforto dos seus bancos, dizendo: "Ora ali estão a morte e os seus heróis. Vejamos como se disputam e seduzem."

Não conhecerão pois o borror e a piedade porque os seus olbos se acham escudados. Nada sabem dos cantos e das danças, não soltarão o uivo nem o riso.

Talvez o sangue se lhes arrefeça um pouco, e pensarão: "Não há razões para ter medo. Nem sequer deverei tomar partido.» [...]

\footnotetext{
${ }^{9}$ No final da peça esta dimensão é enunciada no discurso de Tirésias com que termina a acção: "Retiremo-nos nós agora, os sem idade, os que temos ligado céus e Terra. Os Magos do Oriente, os Chamans das estepes, os áugures e todos os que ainda vagueavam pelos lugares dos homens, sem que a humanidade os sujeitasse. Eis pois que os mortos se recolherão para sempre e não mais poderão ser vistos nem ouvidos.» (p.58)

${ }^{10}$ Esta é aliás, segundo Vítor Manuel de Aguiar e Silva, Teoria da Literatura, Coimbra, Almedina, 1983, p.604, uma das possibilidades de intervenção do autor dramático no texto.

${ }^{11}$ A dimensão xamânica do escritor, mediador entre espaços, fronteiras e culturas, é particularmente discutida em Aleida Assmann, «Texte, Spuren, Abfall: die wechselnden Medien des kulturellen Gedächtnisses", Literatur und Kulturwissenschaften. Positionen, Theorien, Modelle (Hartmut Böhme, Klaus Scherpe eds.) Reinbek bei Hamburg, Rowohlt, 1996, p. 96.

${ }^{12}$ Segundo a lenda, Tirésias teria tido a experiência dos dois sexos. Ao passear no monte Citera teria visto duas serpentes que copulavam e ao separá-las teria sido castigado e transformado em mulher Passados sete anos e repetindo-se a mesma situação, Tirésias teria então recuperado o seu sexo original. Seria devido à sua experiência dos dois sexos que Tirésias teria sido convidado por Hera e Zeus a decidir se no acto sexual o maior prazer cabia ao homem ou à mulher. Tirésias teria então respondido que à mulher cabia a maior parte do prazer sexual, pelo que Hera o teria castigado com a cegueira e Zeus o recompensara com o dom da profecia. Pierre Grimal, Dicionário de Mitologia Greco-Latina, Pub. Dom Quixote, Lisboa 1997, p. 450.
} 
E dirão: "Afinal acaba bem, visto que é recontado ao longo das idades. Acaba bem já que faz parte da memória."

E, sentindo-se assim defendidos dos velhos e divinos pavores, suspirarão de alívio. Porque não são e não podiam ser Antígona.

Aliás tais coisas nunca aconteceram. (pp.22-23)

Esta primeira intervenção de Tirésias tem o efeito de distanciar o acontecimento do acontecido. Activando os pré-conhecimentos do espectador acerca do mito, da tragédia e do aristotélico e catártico sentimento de «terror e piedade», Tirésias documenta a deslegitimação do acontecimento trágico, a sedimentação do mito na memória, revelando os acontecimentos que se vão seguir como simulacros, mimemas de uma memória cultural que actua como força xamânica na economia do texto. A irrealidade ou virtualidade do representado sugere, deste modo, uma construção dramática espectrográfica, materializada numa textualidade virtual que faz as personagens surgir perante nós como corpos fantasmáticos, incorporações do repositório da memória cultural ${ }^{13}$ e não apenas da ideia abstracta, para utilizar uma produtiva expressão de Jacques Derrida na obra Spectres de Marx:

La production du fantôme, la constitution de l'effet fantôme, ce n'est pas simplement une spiritualisation, ni même l'autonomisation de l'esprit, de l'idée ou de la pensée [...].Non, une fois cette autonomisation effectuée, avec l'expropriation ou l'aliénation correspondantes, et alors seulement, le moment fantomal lui survient, il lui ajoute une dimension supplémentaire, un simulacre, une aliénation ou une expropriation de plus. À savoir un corps! Une chair (Leib)! Car il n'y a pas de fantôme, il n'y a jamais de devenir-spectre de l'esprit sans au moins une apparence de chair, dans un espace de visibilité invisible, comme dis-parâ̂tre d'une apparition. Pour qu'il y ait du fantôme, il faut un retour au corps, mais

\footnotetext{
13 Sobre o conceito de memória cultural vd. Jan Assmann, Das kulturelle Gedächtnis, München, Beck,1999.
} 
à un corps plus abstrait que jamais. Le processus spectrogène répond donc à une incorporation paradoxale. Une fois l'idée ou la pensée (Gedanke) détachées de leur substrat, on engendre du fantôme en leur donnant du corps. Non pas en revenant au corps vivant dont sont arrachées les idées ou les pensées, mais en incarnant ces dernières dans un autre corps artefactuel, un corps prothétique, un fantôme d'esprit, on pourrait dire un fantôme de fantôme[...]. ${ }^{14}$

A representação surge sob o signo da modalidade espectral, e o texto dramático assume-se como spectrographie, uma grafia obituária, numa dialéctica que combina o passado do mito, o presente isocrónico da acção e o futuro das textualidades em confronto, ${ }^{15}$ a ausência e a presença ${ }^{16}$. Os dois planos de acção que o discurso de Tirésias introduz - o plano dos vivos, dividido em duas partes, uma primeira constituindo um diálogo sobre a vida das mulheres e um segundo contendo os mitemas do tema antigónico na versão de Hélia Correia e o plano dos mortos, constituído pelo diálogo aporístico da Antígona morta e da Ama, materializam esta espécie de escrita espectral, constituindo-se naquilo que Jacques Derrida designa por «espectropoética» (spectropoétique), uma transposição fantasmática e subversiva, de um mundo morto, o mundo do mito, para um mundo de vivos, realizada através do simulacro da ficção dramática que a-presenta o mito, isto é torna-o presença no mundo dos vivos e, baseando-se numa estrutura de repetição, re-presenta duplamente a sua presença na esfera da negação simbólica, o espaço dos mortos.

Se o discurso de Tirésias funciona como um momento estabilizador da acção, entre a presença e a ausência, o diálogo da Antígona morta e da Ama representa o seu contrário. Embora se inscreva na tradição clássica dos Diálogos

\footnotetext{
${ }^{14}$ Jacques Derrida, Spectres de Marx, Paris, Galilée, 1993, pp. 202-203.

${ }^{15}$ No filme de Ken McMullen Ghost Dance, em que participa em 1982, Jacques Derrida refere a propósito da temporalidade do fantasmático: «I believe on the contrary that the future belongs to ghosts, and that modern image technology, cinema, telecommunications, etc., are only increasing the power of ghosts.» Bennington, op.cit., p. 349.

${ }^{16}$ Jacques Derrida, op.cit., p. 294.
} 
dos Mortos (Nekrikoi Dialogoi) do escritor cristão Luciano (160 d.C.), ao passo que o estado orgânico da morte contribui no texto de Luciano para legitimar a verdade dos diálogos, uma vez perdidos os interesses que movem os mortos em vida, o diálogo da Antígona e da Ama mortas não contribui para legitimar o discurso dos vivos, mas antes para o desestabilizar, relativizando e mesmo negando a validade das suas afirmações. A nível dramático, tanto o discurso das mortas como o discurso de Tirésias são representações da função do coro trágico, comentando e apresentando a acção dos vivos, exercendo sobre eles a sua força, de um lado legitimadora, de outro subversiva. A impenetrabilidade entre as esferas dos vivos e das mortas demonstra a aporia desta encenação da "possibilidade do impossível». A morte de Antígona vista pela própria Antígona apresenta afinal a potencialidade subversiva de uma escrita espectral sobre a escrita vital, aí residindo a estranheza da retórica dramática. Se, por um lado, a evocação dramática de Antígona se entende como uma revitalização dos mortos, tornando presente o passado do passado que a herança trágica corporiza, por outro, o diálogo das mortas relativiza esta estratégia de re-presentação, mostrando a vanidade da re-encenação e colocando o drama no espaço híbrido entre o relativismo da dimensão sócio-comunicativa do presente do público e a vontade de tornar presente a história mítica do passado. Exemplos desta desestabilização e deste situar do drama no espaço indefinido, in-between, tempos, espaços, histórias e públicos, são as afirmações subversivas da Ama, ou a desesperada tentativa da Antígona morta de agir no tempo dos vivos. Assim, quando no início do diálogo dos vivos, Antígona questiona a Ama acerca da sua cadelita, esta responde-lhe que o animal a deverá ter seguido para o exílio, mas a Ama morta nega esta afirmação, dizendo que a matou (p.23).

Do mesmo modo, no final do texto, a própria Antígona morta tenta intervir no espaço dos vivos, para avisar a Antígona viva da futilidade de uma ousadia que leva à morte. O discurso de Antígona na morte, neste derradeiro espaço de fronteira, é o discurso da suspeição do discurso dos vivos e da sua relativização. O paradigma antigónico radicaliza aqui a sua dimensão transgressora 
através de uma deslegitimação do canonizado acto de revolta que conduz à morte, o momento transgressivo por excelência. Na economia dramática, a desilusão de Antígona na morte leva-a a dirigir-se ao seu alter ego vivo, dizendo: «É preciso dizer-lhe que não avance mais, que não há glória alguma em tudo isto!» (p.56) . Mais à frente refere em tom de resignação «[...]É bem preferível a vida miserável das mulheres.» (p.57) Antígona morta apresenta-se aqui como uma verdadeira anti-Antígona, uma personagem anti-trágica, demonstrando a não reversabilidade entre os domínios e a incapacidade de a escrita legitimar a morte. ${ }^{17}$ A ousadia da Antígona viva é, assim, uma força quase erótica de jogar e perder, de provar a existência até aos seus limites na morte, e de realizar eroticamente a vida através da realização deste derradeiro ritual de passagem:

Tenho medo e no entanto parece-me que é o medo que eu amo. Esta agonia. Faz-me gelar o sangue, os dedos adormecem-me, o coração contrai-se numa angústia finíssima. Sinto-me levemente estonteada e escorre-me um suor por entre os seios. Ó Ama, imaginei que fosse assim a noite em que visse o meu esposo entrar no quarto pela primeira vez. (pp. 53-54)

A experiência da morte representa, contudo, a anulação da memória, da sensação, a própria designação «experiência da morte», tornando-se impossível na escrita, por ser inimaginável, impenetrável, a consagração da negatividade. A "felicidade e o sofrimento» (p.56), que caracterizam o mundo dos vivos, estão ausentes do mundo das mortas, onde o tempo está suspenso e se torna em espaço, o espaço do campo de asfódelos que têm de atravessar. Na verdade, a dimensão obituária da literatura, que Peter Brooks, na obra Reading for

\footnotetext{
${ }^{17}$ Jacques Derrida refere no texto Aporias a apropriação da morte na escrita como um movimento de dissimulação virtual: "Who will guarantee that the name, the ability to name death (like that of naming the other and it is the same) does not participate as much in the dissimulation of the "as such" of death as in its revelation, and that language is not precisely the origin of the nontruth of death, and of the other?» Jacques Derrida, Aporias (trad. Thomas Dutoit), Stanford, Stanford University Press, 1993, p. 76
} 
the Plot. Design and Intention in Narrative, designa como a busca de «[...] a retrospective knowledge that comes after the end, which in human terms places it on the far side of death", ${ }^{18}$ é negada no espaço desta poética espectral, onde depois da morte o desconhecimento se aprofunda.

A falência da linguagem, baseada na arbitrariedade, fundamenta a sua potencialidade subversiva, a capacidade de desregular, de questionar, de transgredir, de ultrapassar os limites do simbólico e do representativo, uma força semelhante à que o fantasma, esse revenant da morte exerce sobre o mundo dos vivos. O diálogo das mortas torna-se, deste modo, num acto de experiência limite da linguagem, narcisisticamente fechada sobre si e a sua própria morte. $\mathrm{Na}$ verdade, para este exercício espectral nenhum tema seria mais adequado do que o de Antígona, um nome que etimologicamente contém em si as raízes da negação. Antígona, a mulher que nasce para morrer, a que afirma a morte e despreza a vida, Antígona o fantasma da memória, a anti-mulher que o drama encena numa dupla morte. De facto, se a Antígona viva é já o anunciar da sua negação, a Antígona morta funciona como um pleonasmo representacional a dois níveis. A nível textual, a Antígona morta é um fantasma do fantasma anunciado no texto dos vivos; a nível da esfera da representação, a Antígona morta é de novo um pleonasmo porque reforça ou repete o lugar que, segundo Lacan, à mulher é devido nesta esfera, o de morta. Quando Edgar Allan Poe refere em The Philosophy of Composition, que "The death of a beautiful woman is, unquestionably, the most poetical topic in the world ${ }^{19}$ descreve uma atitude inerente à própria ordem da cultura, a de que a mulher representando o marginal em si, o Outro da cultura, a legitima através da sua morte sacrificial. ${ }^{20}$

Lacan estuda a Antígona de Sófocles no seminário de 1960, «L'essence de la tragédie. Un commentaire de l'Antigone de Sophocle», organizado em três par-

\footnotetext{
18 Peter Brooks, Reading for the Plot. Designs and Intention in Narrative, New York, Knopf, 1984,p.61.

${ }^{19}$ Edgar Allan Poe, Collected Writings, Harmondsworth, Middlesex, Penguin,1984, p. 19.
} 
tes: «L'éclat d'Antigone», "Les articulations de la pièce» e "Antigone dans l'entre deux-morts». O psicólogo francês considera que os termos «morte», «mulher», "O nada» e "beleza» são categorias intermutáveis reunidas na caracterização de Antígona. ${ }^{21} \mathrm{O}$ argumento lacaniano de que a mulher é o nada desenvolve a noção de que o feminino é definido apenas em relação ao significante "homem», apontando para o facto de que tal definição é sempre imaginária, tendo como função apoiar a fantasia de completude e realização masculinas. A designação "mulher morta» ou "a morta» representaria, deste modo, o pleonasmo da cultura, uma enfatização do papel atribuído simbolicamente ao sexo feminino.

Escrever a morte da mulher através do mito de Antígona é, assim, reflectir sobre a negação da negação, ou, paradoxalmente, sobre a negação do feminino e a sua confirmação enquanto locus da morte. A assinatura Antígona representa por si só a sua negação, a contra-signatura no dizer de Derrida, ${ }^{22}$ as marcas da sua aniquilação enquanto Antígona. O texto de Hélia Correia é o equivalente textual desta contra-assinatura. A espectrografia deste drama transporta para o palco da representação a imagem fantasmática da revenant Antígona, o fantasma do mito no mundo dos vivos, confrontando-o com a arrivant absoluta, ${ }^{23}$ a Antígona morta, que não tem lugar, situando-se no espaço aporístico da fronteira, o campo de asfódelos que os mortos devem atravessar.

\footnotetext{
${ }^{20}$ Como refere Elisabeth Bronfen: "As the outsider per se, woman can also come to stand for the complete negation of the ruling norm, for the element which disrupts the bonds of normal convention and the passage through which that threat to the norm is articulated. [...] Over her dead body, cultural norms are reconfirmed or secured, whether because the sacrifice of the virtuous, innocent woman serves a social critique and transformation or because a sacrifice of the dangerous woman reestablishes an order that has momentarily suspended due to her presence.» Elisabeth Bronfen, Over Her Dead Body Death, Femininity and the Aesthetic, Oxford, Manchester University Press, 1992, p.181.

${ }^{21}$ Jacques Lacan, Die Ethik der Psychoanalyse (trad. Norbert Haas, hg. Jacques-Allain Miller), Berlin, Quadriga, 1996, pp.293-346.

${ }_{22}^{22}$ Jacques Derrida, Feu la cendre, Paris, Editions des femmes, 1987, p. 22.

23 "What we call here the arrivant, the most arrivant among all arrivants, the arrivant par excellence, is whatever, whoever, in arriving, does not cross a threshold separating two identifiable places, the proper and the foreign, the proper of the one and the proper of the other, as one would say that the citizen of a given identifiable country crosses the border of another country as a traveler, an emigré or a political exile, a refuge or someone who has been deported, an immigrant worker, a student or a researcher, a diplomat or a tourist.» Jacques Derrida, Aporias, pp.33-34.
} 
Constituindo-se entre o que Wolfgang Iser determina como a condição ficcional, e portanto de simulacro, inerente ao literário, e o imaginário do leitor, ${ }^{24}$ o texto de Hélia Correia confronta-nos como o exercício de escrita dramática de uma poética espectral, definida entre a presença do drama e a ausência do fantasma mitológico, a diferância de uma escrita feminina sobre a morte de uma mulher e o modelo canónico deste discurso, o tempo presente dos vivos e a ausência do tempo das mortas, a história e a memória.

\section{II - Spectropoétique e escrita dramática em Perdição}

Podemos assim subsumir as características essenciais deste exercício de poética espectral em quatro alíneas:

1 - Simulacro - O drama constitui-se como um exercício de ontologia espectral, iniciado com o canto ritual das bacantes que transporta o espectador e o leitor para o longínquo mundo dos rituais, dos tempos cíclicos e ausentes da história, onde a verdade do mito e a dimensão moralizante da fonte sofocliana se transformam num mero exercício de linguagem, um fantasma de fantasma, que, jogando com a disseminação grafémica da palavra ontologia e do verbo inglês to haunt (assombrar), transporta a ontologia para a esfera da hauntologia ${ }^{25}$. Perdição não é, deste modo, um mero avatar de Antígona, mas uma contra-assinatura do mito e da sua geminação com o tema do amor de perdição, igualmente subvertido pela repetição dramática do refrão «amor» e sua desconstrução. A virtualidade do texto manifesta-se igualmente a nível

\footnotetext{
${ }^{24}$ Wolfgang Iser, Das Fiktive und das Imaginäre. Perspektiven literarischer Anthropologie, Frankfurt am Main, Suhrkamp, 1993.

${ }^{25}$ Este termo é cunhado por Jacques Derrida e designa uma ontologia espectral, virtual, constituindo-se através da disseminação grafémica da palavra a partir dos morfemas haunt ( do verbo inglês to haunt, assombrar) e ontologia. Cf. Jacques Derrida, Spectres de Marx, pp.274-275.
} 
estrutural, através da destruição do princípio que, segundo Hegel, fundamenta a conflitualidade trágica, o princípio da colisão dramática ${ }^{26}$. As antinomias do texto entre jovens e velhos, homens e mulheres, o discurso da ordem e da desordem, são oposições naturais pré-existentes, mas que não decorrem do desenvolvimento da acção, que deste modo flui para a catástrofe inevitável, determinada pela assinatura antigónica.

Podemos então dizer que este drama se encena na invisibilidade, para utilizar a terminologia de Hans Belting, ou seja, encena, negando, o que lhe subjaz. Apesar da negação dos seus elementos constitutivos, a obra de arte dramática constrói-se a partir da sua invisibilidade, atingindo formalmente, através do jogo interactivo com a memória do espectador/leitor, o lugar de avatar do drama trágico de Antígona. ${ }^{27}$

2 - Estranhamento - A virtualidade e espectralidade do texto dramático revelam-se através de uma dupla estratégia de estranhamento a nível inter e intratextual. A nível intertextual verifica-se relativamente ao modelo da heroína clássica Antígona e dos seus pares, na tragédia canónica de Sófocles, uma estratégia dialéctica articulada entre aquilo a que Jonathan Culler chamaria uma "hermenêutica da suspeição" (hermeneutics of suspicion) e "hermenêutica da recuperação» (bermeneutics of recovery) ${ }^{28}$, isto é a negação do modelo clássico e a busca incessante de o recuperar. Jogando com o modelo clássico de Sófocles, aqui recuperado na negação, Antígona é referida como uma rapariga com uma certa dose de marginalidade, quase um animal deslocado da ordem da cultura e sem ter integrado as regras mínimas da convivência social. Não se

\footnotetext{
${ }^{26}$ G.W.F. Hegel, Vorlesungen über die Ästhetik III. Werke 15, (hg. Eva Moldenhauer, Karl Markus Michel), Frankfurt am Main, Suhrkamp, 1986, p. 549.

${ }^{27}$ Hans Belting é um historiador de arte e desenvolve a sua concepção da obra de arte invisível (unsichtbares Kunstwerk) para analisar a redefinição dos paradigmas artísticos e culturais na Pós-Modernidade. Segundo Belting é a "Aura» benjaminiana de uma memória colectiva que estas obras transportam em si que as legitima. Hans Belting, Das unsichtbare Kunstwerk. Die modernen Mythen der Kunst, Munique, Beck, 1998, p. 483.

${ }^{28}$ Jonathan Culler, op.cit., p. 68.
} 
lava, não domina «a arte das mulheres», essa forma de mascarada que modela o sexo cultural na óptica de Monique Wittig e Judith Butler ${ }^{29}$. A Antígona desta Perdição radicaliza a marginalidade da sua congénere sofocliana. É designada pelos outros como histérica, alucinada, alguém que «Tinha tudo trocado na cabeça. [...] Não respeitava a sucessão dos tempos.» (p. 57). Por um processo de estranhamento e distanciamento, esta Antígona, que jogou e perdeu, a rapariguinha ousada, radicaliza o paradigma da exclusão do feminino, não o negando como o modelo de Sófocles, mas transportando-o para uma discursividade erótica e sensual que subjaz na economia interna do texto à construção fantasmática dos actantes. Esta interage com uma textualidade corpórea, radical e desregrada, que revela um processo de estranhamento relativamente à ordem "normal" canónica do discurso. Transportando a tónica central da acção de uma esfera masculina, a do direito do homem à sepultura, para uma eminentemente feminina - a busca do amor e da identidade femininas, o discurso de Hélia Correia constitui-se numa forma erótica radical, uma semântica sensual que toca o grotesco, como no coro das bacantes:

Pelo fogo da lingua,

pelo sopro e o contágio da língua.

Pela boca,

os buracos do corpo que nos ligam

ao estrume

e ao alimento.

Os buracos do corpo onde entra o homem

e escorrem as sangrias,

por onde nos rebentam as crianças. (p.17)

${ }^{29}$ Judith Butler, Gender Trouble, London, Routledge, 1990. 
Ao nível intratextual, Hélia Correia cria o estranhamento, cindindo o discurso de e sobre a mulher através de uma linguagem grotesca que, embora subvertendo o discurso hegemónico, evoca a dimensão arcaizante de um primitivo ethos feminino, activando em simultâneo no espectador/leitor os mecanismos de distanciamento e atracção. Encenada pelas personagens femininas, as bacantes, Eurídice, Antígona e a Ama, aproxima-as de uma dimensão arcaica, pré-cultural, simultaneamente destrutiva e renovadora. O texto surge permeado de gritos :»[...] raparigas euoi, euoi, iú,iú, espojadas, rastejantes, alegres como bichos, apavoradas como bichos. Bichos. À roda, à roda, será isto o amor?» (p.22) Sexualidade e morte combinam-se eroticamente numa textualidade fantasmática, que encena o corpo simbolicamente "morto» da mulher na semântica violentamente sensual do seu discurso, um body writing que realiza no eixo da horizontalidade sintagmática da escrita a vida que o paradigma antigónico lhe nega. A animalidade feminina - veja-se que Antígona é referida mais à frente como um "animalzinho descarado» (p.39) - surge intimamente ligada à questão que funciona como o refrão do coro das bacantes e que se transforma em Leitmotiv do discurso, a pergunta sobre a identidade do amor. Sexualidade para as bacantes, "matéria de deuses, feita para ser cantada" (p.34) para Eurídice; "Coisa de mulheres» (p.34) para a Ama, a decifração do enigma do amor surge para Antígona no momento de sensualidade radical da morte.

3 - Limites-Periferias - A espectropoética constrói a encenação dramática como instituição limítrofe, periférica, oscilando entre planos, tempos e espaços, sem em nenhum se fixar. Em conflito está o que Isabel Allegro de Magalhães denomina o tempo de Aquiles, ${ }^{30}$ o tempo linear dos homens, marcado pelo sangue das guerras (p.36), o tempo dos mortos com história (p.42), e o tempo cíclico de Penélope, o tempo das mulheres. ${ }^{31}$ Estas, seres deslocados da ordem

\footnotetext{
${ }^{30}$ Isabel Allegro de Magalhães, O Tempo das Mulheres, Lisboa, Imprensa Nacional Casa da Moeda, 1987, pp.40 ss.

${ }^{31}$ Ibid., p. 19.
} 
do tempo e do espaço, vivem o tempo sancionado por Dioniso, o tempo acrónico que se situa fora da história, no espaço da memória. É um tempo circular, definido pelo ritmo biológico «[...]entre o sangue dos meses e o sangue dos partos [...]»(p.34), os teares, o armazém e a lareira. Tal como aos excluídos, às mulheres apenas resta "[...]a fala e a memória[...]» (p.38), que a poética espectral deste drama de Hélia Correia exorta.

Os limites do tempo são coincidentes com as construções limítrofes desta poética de espectros, que se move nas periferias do consentido, entre a ordem da palavra e a desordem da fala, entre o espaço político da cidade, que a sala do trono representa, e o pátio do palácio, onde dominam as mulheres. A construção a três planos permite o cruzar das fronteiras do espaço, mas não a alteração dos lugares dos sexos e dos poderes que a morte acaba, afinal, por consagrar.

4 - Aporia - A poética espectral realiza-se por fim na aporia do discurso sobre a morte, um discurso fora do espaço, da temporalidade e da razão, que realiza a possibilidade do impossível: deixar Antígona falar a sua morte. Deslocado sem possibilidade de encontrar um lugar, o discurso espectral não regressa, mas parte eternamente num movimento de exílio, de deslocação nomádica, apresentando a aporia de buscar na ausência - na morte de Antígona - a razão para a presença.

A incapacidade do corpo da morte penetrar no espaço da vida é contudo compensada por um novo corpus - e recordemos a aproximação do corpus, enquanto significante de cadáver e corpus, enquanto conjunto imortal de textos - o texto dramático, que não realiza a lei da morte, permanecendo como realização espectral da autora xamã, que agora, como Tirésias, nos incita a retirar.

Retiremo-nos nós agora, os sem idade, os que temos ligado céus e Terra. Os Magos do Oriente, os Xamãs das estepes, os Áugures e todos os que ainda vagueavam pelos lugares dos homens, sem que a humanidade os sujeitasse. Eis pois que os mortos se recolherão para sempre e não mais poderão ser vistos nem ouvidos. (p.58) 



\section{Série}

\section{Documentos}

Imprensa da Universidade de Coimbra

Coimbra University Press

2006

- $\mathrm{U}$

C • 